\title{
종 SMART GRID: MARKET OPPORTUNITIES AND CHALLENGES
}

\author{
Raj Kumar Yadav, Vineet Kumar, Hemant Shriwastava \\ E-Mail Id: rkyee1990@gmail.com \\ Assistant Professor, Department of Electrical Engineering, VIT, Jaipur, Rajasthan (India)
}

\begin{abstract}
A smart grid is an electrical grid which includes a variety of operational and energy measures including smart meters, smart appliances, renewable energy resources, and energy efficient resources. Electronic power conditioning and control of the production and distribution of electricity are important aspects of the smart grid. Smart grid policy is organized in Europe as Smart Grid European Technology Platform.

Roll-out of smart grid technology also implies a fundamental re-engineering of the electricity services industry, although typical usage of the term is focused on the technical infrastructure.
\end{abstract}

\section{INTRODUCTION}

It is the policy to support the modernization of the Nation's electricity transmission and distribution system to maintain a reliable and secure electricity infrastructure that can meet future demand growth and to achieve each of the following, which together characterize a Smart Grid: (1) Increased use of digital information and controls technology to improve reliability, security, and efficiency of the electric grid. (2) Dynamic optimization of grid operations and resources, with full cyber-security. (3) Deployment and integration of distributed resources and generation, including renewable resources. (4) Development and incorporation of demand response, demand-side resources, and energy-efficiency resources. (5) Deployment of 'smart' technologies (real-time, automated, interactive technologies that optimize the physical operation of appliances and consumer devices) for metering, communications concerning grid operations and status, and distribution automation. (6) Integration of 'smart' appliances and consumer devices. (7) Deployment and integration of advanced electricity storage and peak-shaving technologies, including plug-in electric and hybrid electric vehicles, and thermal storage air conditioning. (8) Provision to consumers of timely information and control options. (9) Development of standards for communication and interoperability of appliances and equipment connected to the electric grid, including of the infrastructure serving the grid. (10) The identification and lowering of unreasonable or unnecessary barriers to adoption of smart grid technologies, practices, and services" in markets.

\section{BACKGROUND}

The first alternating current power grid system was installed in 1886 in Great Barrington, Massachusetts. At that time, the grid was a centralized unidirectional system of electric power transmission, electricity distribution, and demand-driven control.

Through the 1970s to the 1990s, growing demand led to increasing numbers of power stations. In some areas, supply of electricity, especially at peak times, could not keep up with this demand, resulting in poor power quality including blackouts, power cuts, and brownouts. Increasingly, electricity was depended on for industry, heating, communication, lighting, and entertainment, and consumers demanded ever higher levels of reliability.

Towards the end of the 20th century, electricity demand patterns were established: domestic heating and airconditioning led to daily peaks in demand that were met by an array of 'peaking power generators' that would only be turned on for short periods each day. The relatively low utilization of these peaking generators (commonly, gas turbines were used due to their relatively lower capital cost and faster start-up times), together with the necessary redundancy in the electricity grid, resulted in high costs to the electricity companies, which were passed on in the form of increased tariffs. In the 21st century, some developing countries like China, India and Brazil were seen as pioneers of smart grid deployment.

\section{MODERNIZATION OPPORTUNITIES}

Since the early 21 st century, opportunities to take advantage of improvements in electronic communication technology to resolve the limitations and costs of the electrical grid have become apparent. Technological limitations on metering no longer force peak power prices to be averaged out and passed on to all consumers equally. In parallel, growing concerns over environmental damage from fossil-fired power stations has led to a desire to use large amounts of renewable energy. Dominant forms such as wind power and solar power are highly variable, and so the need for more sophisticated control systems became apparent, to facilitate the connection of sources to the otherwise highly controllable grid. Power from photovoltaic cells (and to a lesser extent wind turbines) has also, significantly, called into question the imperative for large, centralized power stations. The rapidly 


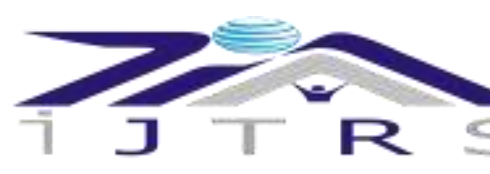

\section{International Journal of Technical Research \& Science}

falling costs point to a major change from the centralized grid topology to one that is highly distributed, with power being both generated and consumed right at the limits of the grid. Finally, growing concern over terrorist attack in some countries has led to calls for a more robust energy grid that is less dependent on centralized power stations that were perceived to be potential attack targets.

\section{FEATURES OF THE SMART GRID}

The smart grid represents the full suite of current and proposed responses to the challenges of electricity supply. Because of the diverse range of factors there are numerous competing taxonomies and no agreement on a universal definition.

\subsection{Reliability}

The smart grid makes use of technologies such as state estimation, that improve fault detection and allow selfhandling of the network without the intervention of technicians. This will ensure more reliable supply of electricity, and reduced vulnerability to natural disasters or attack.

\subsection{Flexibility in Network Topology}

Next-generation transmission and distribution infrastructure will be better able to handle possible bidirectional energy flows, allowing for distributed generation such as from photovoltaic panels on building roofs, but also the use of fuel cells, charging to/from the batteries of electric cars, wind turbines, pumped hydroelectric power, and other sources.

\subsection{Efficiency}

Numerous contributions to overall improvement of the efficiency of energy infrastructure are anticipated from the deployment of smart grid technology, in particular including demand-side management, for example turning off air conditioners during short-term spikes in electricity price, reducing the voltage when possible on distribution lines

\subsection{Load Adjustment}

The total load connected to the power grid can vary significantly over time. Although the total load is the sum of many individual choices of the clients, the overall load is not a stable, slow varying, increment of the load if a popular television program starts and millions of televisions will draw current instantly. Traditionally, to respond to a rapid increase in power consumption, faster than the start-up time of a large generator, some spare generators are put on a dissipative standby mode

\subsection{Sustainability}

The improved flexibility of the smart grid permits greater penetration of highly variable renewable energy sources such as solar power and wind power, even without the addition of energy storage.

\subsection{Market-Enabling}

The smart grid allows for systematic communication between suppliers (their energy price) and consumers (their willingness-to-pay), and permits both the supplier and the consumers to be more flexible and sophisticated in their operational strategies.

\section{TECHNOLOGY}

The bulk of smart grid technologies are already used in other applications such as manufacturing and telecommunications and are being adapted for use in grid operations. ${ }^{[25]}$

$>$ Integrated communications

$>$ Sensing and measurement

$>$ Smart meters.

$>$ Pharos measurement units.

$>$ Distributed power flow control

$>$ Smart power generation using advanced components

$>$ Power system automation

\subsection{Major Programs}

\subsubsection{IntelliGrid}

Created by the Electric Power Research Institute (EPRI), Intelligent Grid architecture provides methodology, tools, and recommendations for standards and technologies for utility use in planning, specifying, and procuring IT-based systems, such as advanced metering, distribution automation, and demand response. The architecture also provides a living laboratory for assessing devices, systems, and technology. 


\subsubsection{Modern Grid Initiative}

MGI is a collaborative effort between the U.S. Department of Energy (DOE), the National Energy Technology Laboratory (NETL), utilities, consumers, researchers, and other grid stakeholders to modernize and integrate the U.S. electrical grid. DOE's Office of Electricity Delivery and Energy Reliability (OE) sponsor the initiative, which builds upon Grid 2030 and the National Electricity Delivery Technologies Roadmap and is aligned with other programs such as Grid Wise and Grid Works.

\subsubsection{Solar Cities}

In Australia, the Solar Cities program included close collaboration with energy companies to trial smart meters, peak and off-peak pricing, remote switching and related efforts. It also provided some limited funding for grid upgrades.

\subsubsection{Smart Grid Modeling}

Many different concepts have been used to model intelligent power grids. They are generally studied within the framework of complex systems. In a recent brainstorming session, the power grid was considered within the context of optimal control, ecology, human cognition, glassy dynamics, information theory, microphysics of clouds, and many others. Here is a selection of the types of analyses that have appeared in recent years.

\section{MARKET OUTLOOK}

In 2009 , the US smart grid industry was valued at about $\$ 21.4$ billion - by 2014 ; it will exceed at least $\$ 42.8$ billion. Given the success of the smart grids in the U.S., the world market is expected to grow at a faster rate, surging from $\$ 69.3$ billion in 2009 to $\$ 171.4$ billion by 2014 . With the segments set to benefit the most will be smart metering hardware sellers and makers of software used to transmit and organize the massive amount of data collected by meters. ${ }^{[60]}$ Recently, the World Economic Forum reported a transformational investment of more than $\$ 7.6$ trillion is needed over the next 25 years (or $\$ 300$ billion per year) to modernize, expand, and decentralize the electricity infrastructure with technical innovation as key to the transformation.

\section{OPPOSITIONS AND CONCERNS}

Most opposition and concerns have centered on smart meters and the items (such as remote control, remote disconnect, and variable rate pricing) enabled by them. Where opposition to smart meters is encountered, they are often marketed as "smart grid" which connects smart grid to smart meters in the eyes of opponents. Specific points of opposition or concern include:

$>$ consumer concerns over privacy, e.g. use of usage data by law enforcement

$>$ social concerns over "fair" availability of electricity

$>$ concern that complex rate systems (e.g. variable rates) remove clarity and accountability, allowing the supplier to take advantage of the customer

$>$ concern over remotely controllable "kill switch" incorporated into most smart meters

$>$ social concerns over Enron style abuses of information leverage

$>$ concerns over giving the government mechanisms to control the use of all power using activities

$>$ concerns over RF emissions from smart meters

\section{OTHER CHALLENGES TO ADOPTION}

Before a utility installs an advanced metering system, or any type of smart system, it must make a business case for the investment. Some components, like the power system stabilizers (PSS) installed on generators are very expensive, require complex integration in the grid's control system, are needed only during emergencies, and are only effective if other suppliers on the network have them. Without any incentive to install them, power suppliers don't. Most utilities find it difficult to justify installing a communications infrastructure for a single application (e.g. meter reading). Because of this, a utility must typically identify several applications that will use the same communications infrastructure - for example, reading a meter, monitoring power quality, remote connection and disconnection of customers, enabling demand response, etc. Ideally, the communications infrastructure will not only support near-term applications, but unanticipated applications that will arise in the future. Regulatory or legislative actions can also drive utilities to implement pieces of a smart grid puzzle. Each utility has a unique set of business, regulatory, and legislative drivers that guide its investments. This means that each utility will take a different path to creating their smart grid and that different utilities will create smart grids at different adoption rates.

Some features of smart grids draw opposition from industries that currently are, or hope to provide similar services. An example is competition with cable and DSL Internet providers from broadband over power line internet access. Providers of SCADA control systems for grids have intentionally designed proprietary hardware, protocols and software so that they cannot inter-operate with other systems in order to tie its customers to the vendor. 


\subsection{Power Theft / Power Loss}

International Journal of Technical Research \& Science

Various "smart grid" systems have dual functions. This includes Advanced Metering Infrastructure systems which, when used with various software can be used to detect power theft and by process of elimination, detect where equipment failures have taken place. These are in addition to their primary functions of eliminating the need for human meter reading and measuring the time-of-use of electricity.

The worldwide power loss including theft is estimated at approximately two-hundred billion dollars annually. Electricity theft also represents a major challenge when providing reliable electrical service in developing countries.

\section{REFERENCES}

[1] "Federal Energy Regulatory Commission Assessment of Demand Response \& Advanced Metering" (PDF). United States Federal Energy Regulatory Commission. United States Federal Energy Regulatory Commission.

[2] "Federal Energy Regulatory Commission Assessment of Demand Response \& Advanced Metering" (PDF).

[3] "Smart Grids European Technology Platform | www.smartgrids.eu". smartgrids.eu. 2011. Retrieved 2011-1011.

[4] J. Torriti, Demand Side Management for the European Supergrid Energy Policy, vol. 44, pp. 199-206, 2012.

[5] "The History of Electrification: The Birth of our Power Grid". Edison Tech Center. Retrieved November 6, 2013.

[6] Mohsen Fadaee Nejad, AminMohammad Saberian and Hashim Hizam (June 3, 2013). "Application of smart power grid in developing countries". 7th International Power Engineering and Optimization Conference (PEOCO). IEEE.doi:10.1109/PEOCO.2013.6564586.

[7] Berger, Lars T.; Iniewski, Krzysztof, eds. (April 2012). Smart Grid - Applicacions, Communications and Security. John Wiley and Sons. ISBN 978-1-1180-0439-5.

[8] Smart Grid Working Group (June 2003). "Challenge and Opportunity: Charting a New Energy Future, Appendix A: Working Group Reports" (PDF). Energy Future Coalition. Retrieved 2008-11-27.

[9] Federal Energy Regulatory Commission staff report (August 2006). "Assessment of Demand Response and Advanced Metering (Docket AD06-2-000)" (PDF). United States Department of Energy: 20. Retrieved 200811-27.

[10] National Energy Technology Laboratory (August 2007). "NETL Modern Grid Initiative — Powering Our 21stCentury Economy" (PDF). United States Department of Energy Office of Electricity Delivery and Energy Reliability: 17. Retrieved 2008-12-06.

[11] "Gridwise History: How did GridWise start?". Pacific Northwest National Laboratory. 2007-10-30. Archived from the original on 2008-10-27. Retrieved 2008-12-03.

[12] Qixun Yang, Board Chairman, Beijing Sifang Automation Co. Ltd., China and .Bi Tianshu, Professor, North China Electric Power University, China. (2001-06-24). "WAMS Implementation in China and the Challenges for Bulk Power System Protection" (PDF).Panel Session: Developments in Power Generation and Transmission - Infrastructures in China, IEEE 2007 General Meeting, Tampa, FL, USA, 24-28 June 2007 Electric Power, ABB Power T\&D Company, and Tennessee Valley Authority. Institute of Electrical and Electronics Engineers. Retrieved 2008-12-01.

[13] Yih-Fang Huang; Werner, S.; Jing Huang; Kashyap, N.; Gupta, V., "State Estimation in Electric Power Grids: Meeting New Challenges Presented by the Requirements of the Future Grid," Signal Processing Magazine, IEEE, vol.29, no.5, pp.33,43, Sept. 2012

[14] Tomoiagă, B.; Chindriş, M.; Sumper, A.; Sudria-Andreu, A.; Villafafila-Robles, R.Pareto Optimal Reconfiguration of Power Distribution Systems Using a Genetic Algorithm Based on NSGA-II. Energies 2013, 6, 1439-1455.

[15] N. A. Sinitsyn. S. Kundu, S. Backhaus (2013). "Safe Protocols for Generating Power Pulses with Heterogeneous Populations of Thermostatically Controlled Loads".Energy Conversion and Management. 67: 297-308. arXiv:1211.0248 .doi:10.1016/j.enconman.2012.11.021.

[16]Energy Future Coalition, "Challenge and Opportunity: Charting a New Energy Future," Appendix A: Working Group Reports, Report of the Smart Grid Working Group.

http://web.archive.org/web/20080910051559/http://www.energyfuturecoalition.org/pubs/app_smart_grid.pdf

[17]Zhang, Xiao; Hug, G.; Kolter, Z.; Harjunkoski, I. (2015-10-01). "Industrial demand response by steel plants with spinning reserve provision". North American Power Symposium (NAPS), 2015: 1-6.

doi:10.1109/NAPS.2015.7335115.

[18]Zhang, X.; Hug, G. (2015-02-01). "Bidding strategy in energy and spinning reserve markets for aluminum smelters' demand response". Innovative Smart Grid Technologies Conference (ISGT), 2015 IEEE Power Energy Society: 1-5. doi:10.1109/ISGT.2015.7131854. 